\title{
Retention in early care at an HIV outpatient clinic in Rio de Janeiro, Brazil, 2000-2013
}

\author{
Daniel S. Silva ${ }^{1,2}$, Raquel B. De Boni ${ }^{3}$, Jordan E. Lake ${ }^{1}$, Sandra W. Cardoso ${ }^{3}$, Sayonara \\ Ribeiro $^{3}$, Ronaldo I. Moreira ${ }^{3}$, Jesse L. Clark ${ }^{1}$, Valdilea G. Veloso ${ }^{3}$, Beatriz Grinsztejn ${ }^{3}$, and \\ Paula M. Luz ${ }^{3}$ \\ ${ }^{1}$ Department of Medicine, David Geffen School of Medicine, University of California, Los Angeles, \\ USA \\ ${ }^{2}$ Boston University School of Medicine, Boston, USA \\ ${ }^{3}$ Instituto Nacional de Infectologia Evandro Chagas, Fundação Oswaldo Cruz, Rio de Janeiro, \\ Brazil
}

\section{Abstract}

Retention in early HIV care has been associated with virologic suppression and improved survival, but remains understudied in Brazil. We estimated retention in early HIV care for the period 20002013, and identified socio-demographic and clinical factors associated with good retention in an urban cohort from Rio de Janeiro, Brazil. Antiretroviral therapy-naïve, HIV-infected persons $\geq 18$ years old linked to care between 2000-2011 were included. Retention in the first two years postlinkage (i.e. early care) was defined by the proportion of six-month intervals with $\geq 1$ HIV laboratory result. "Good" retention was defined as $\geq 1$ HIV laboratory result recorded in at least three intervals. Overall, $80 \%$ of participants met criteria for good retention and retention significantly improved over the study period. Older age, higher education level and early antiretroviral therapy initiation were associated with good retention. Efforts to improve retention in early care in this population should target younger and less-educated HIV-infected persons.

\section{Keywords}

Retention; Acquired Immunodeficiency Syndrome; Highly Active Antiretroviral Therapy; Cohort Studies; Urban Population

\section{Introduction}

HIV is a chronic infection that can be effectively managed with regular medical care that provides HIV-infected persons with timely antiretroviral therapy (ART) and opportunistic infection prophylaxis, monitoring of viro-immunologic response, and management of toxicities and co-morbidities $(1,2)$. Furthermore, engagement in HIV care can facilitate

Corresponding author: D. S. Silva, Author designated to review proofs: D. S. Silva, Boston University School of Medicine, Office of Student Affairs, 72 East Concord St., Boston, MA, 02118, Telephone number: 617-638-4166, Fax number: 617-638-4491, dsilva@bu.edu.

Conflicts of Interests: none 
access to ancillary services, such as risk reduction counseling and social benefits, as well as referrals to specialty care (3-5). Retention during the first 1-2 years in HIV care has specifically been associated with virologic suppression (6-8) and improved survival $(1,9,10)$. Thus, it is important to understand the major drivers of retention in early HIV care to achieve optimal health outcomes for HIV-infected persons and to inform efforts aimed at preventing HIV transmission. In the United States, factors previously associated with improved retention in early HIV care include: older age (8-10), non-black race $(9,10)$, lower baseline CD4+ T lymphocyte counts (CD4) $(8,9)$, faster linkage to care (10), diagnosis of AIDS (10), and non-AIDS-related co-morbidities $(8,9)$.

The scientific literature provides different definitions of retention in HIV care that vary between settings with different resource availability. One widely used method of quantifying retention is by estimating the proportions of individuals completing individual steps of care (HIV diagnosis, linkage to care, retention in care, ART initiation, virologic suppression) in a given calendar year (11-13). In high-income settings, studies have employed more nuanced methods that focus on longitudinal measures of retention based on visit frequency or visit constancy to quantify retention over time (14-17). In resource-limited settings, retention has been defined as being alive and receiving ART at the end of a follow-up period (18) or as being loss to follow-up after a given time interval following a clinic visit, which implicitly assumes that persons lost to follow-up are no longer engaged in care (2). However, tracing studies have shown that many participants who are "lost" to follow-up are actually receiving care elsewhere (2). Therefore, in addition to considering the retention measure applied, it is also important to consider whether a study describes clinic-specific or population-specific retention in HIV care.

Retention in HIV care remains understudied in Brazil. To date only two population-based estimates exist. In 2012 and 2013, the Brazilian Ministry of Health (BMoH) estimated that $82 \%$ and $83 \%$, respectively, of HIV-infected persons linked to HIV care country-wide were retained $(11,19)$. For these estimates, retention was quantified within the context of steps of HIV care and defined based on the presence of at least two CD4 or two HIV-1 RNA measurements or an episode of ART dispensation within the Brazilian public healthcare system in the last 100 days of the calendar year (19). While providing valuable insight into country-wide retention estimates, these estimates do not take into account the longitudinal nature of HIV care. In addition, though the use of labs to measure retention is common practice, these estimates did not discern between labs performed in inpatient or outpatient settings, which may represent different types of care.

Our study had two objectives: First, estimate retention in early HIV care and describe the prevalence of retention in early HIV care over time among HIV-infected persons receiving care at the HIV/AIDS program at the Instituto Nacional de Infectologia Evandro Chagas, Fundação Oswaldo Cruz (INI) in Rio de Janeiro, Brazil. Second, evaluate and quantify associations of socio-demographic and clinical factors with good retention in early HIV care. 


\section{Methods}

\section{Study Design and Participants}

To characterize retention in early HIV care among HIV-infected persons, we conducted a cross-sectional study employing a clinical database at the HIV/AIDS program at INI. All ART-naïve, HIV-infected persons $\geq 18$ years old who initiated HIV care between January 1, 2000 and June 30, 2011 were eligible for inclusion. Linkage to care was defined as the date of the first outpatient CD4 or HIV-1 RNA, or ART initiation date, whichever occurred first. To be included in the present study, participants must have been linked to care at INI within 6 months after their first clinic visit and survived for at least two years post-linkage. Participants who became pregnant during the 2 years post-linkage or participated in a clinical trial were excluded.

\section{Study Site and Data Collection}

The HIV/AIDS program at INI is one of the largest providers of primary, specialty and tertiary care for HIV-infected persons in Rio de Janeiro State, and a national reference center for care, research and training related to HIV/AIDS. At their first clinic visit, participants receive a registration number, an appointment reminder card, and a visit with an HIV care provider. In order to obtain HIV laboratory testing, participants receive prescriptions from their HIV care provider and return at a later date to get their blood drawn. Support staff provide outreach services to patients identified by HIV care providers as missing from care.

A longitudinal, observational HIV clinical database has been maintained at INI since 1998. Cohort procedures have previously been described (20-22). Briefly, data are updated biannually using outpatient and inpatient clinical documentation, including ART regimen data and laboratory results. Trained abstractors record information into standardized forms, which are processed into a central database.

\section{Outcome definition}

Our definitions for linkage and retention were informed by BMoH guidelines, which recommend laboratory monitoring every six months (23). Similar to previous studies $(6,8,10,24,25)$, early HIV care was defined as the first two years after linkage. Retention in early HIV care was measured using visit constancy, and defined by the proportion of sixmonth intervals with $\geq 1 \mathrm{CD} 4$ or HIV-1 RNA measurement in the outpatient setting. Hence, having $\geq 1 \mathrm{CD} 4$ or HIV-1 RNA outpatient measurement in 4, 3, 2, 1 or none of the six-month intervals implied retention in early HIV care of $100 \%, 75 \%, 50 \%, 25 \%$ and $0 \%$, respectively. Good retention in early care was defined as greater than $75 \%$ retention, hereafter referred to as "good" retention. Similar to previous studies $(10,16,24)$, HIV laboratory results were considered surrogates for clinic visits. Inpatient labs were excluded from the retention calculation.

\section{Socio-demographic and clinical factors}

Socio-demographic factors were self-reported at the first clinical visit and are defined below. Age was calculated as the difference between date of birth and date of the first clinic visit. Sex was biological sex at birth. Education level was dichotomized into $>8$ years and $s \&$ 
years of formal education. HIV transmission route was hierarchically categorized as intravenous drug use (IDU, regardless of sexual exposure), men who have sex with men, heterosexual, other, or unknown. Other HIV transmission routes included: vertical transmission $(n=2)$, work accident $(n=3)$, and transfusion $(n=6)$. Race was provider-reported at the first clinic visit and dichotomized as white or non-white.

Clinical factors are defined as follows: Time-to-linkage was calculated by the difference between HIV diagnosis date and the date of linkage to care and dichotomized into $\mathfrak{B}$ months and $>3$ months. ART initiation was defined as the first recorded ART initiation date and categorized into $\leq 3$ months post-linkage, 3-24 months post-linkage and $>24$ months post-linkage. Baseline CD4 was defined as the first CD4 $\_$months post-linkage. Baseline HIV-1 RNA was defined as the first HIV-1 RNA $\leq$ months post-linkage and $\leq 7$ days after ART start date. If linkage was determined by the date of a CD4 or HIV-1 RNA measurement then that value was considered as the baseline. AIDS-defining illness was defined as diagnosis before the end of the early care period using the Centers for Disease Control and Prevention 1993 criteria (26). Metabolic disease was defined as diagnosis before the end of the early care period with $\geq 1$ of the following: diabetes (fasting blood glucose $\geq 126 \mathrm{mg} / \mathrm{dL}$, random blood glucose $\geq 200 \mathrm{mg} / \mathrm{dL}$ or hemoglobin A1c $>6.5 \%$ ), dyslipidemia (LDL $>159$ $\mathrm{mg} / \mathrm{dL}$ or HDL $<40 \mathrm{mg} / \mathrm{dL}$ ), hypercholesterolemia (total cholesterol $>239 \mathrm{mg} / \mathrm{dL}$ ), hypertriglyceridemia (triglycerides $>199 \mathrm{mg} / \mathrm{dL}$ ) or hypertension (diastolic blood pressure $>100 \mathrm{mmHg}$ ). Depression was defined as clinical diagnosis before the end of the early care period. Hospitalization during early care was defined as hospital admissions before the end of the early care period, and dichotomized into $\geq 1$ or no hospitalizations.

\section{Statistical analysis}

Descriptive statistics demonstrate the distribution of socio-demographic and clinical factors overall and by retention category. Statistical differences were assessed by chi-squared test for categorical factors and Kruskal-Wallis test for continuous asymmetric factors. Unadjusted and adjusted binomial logistic regression models were used to quantify the association of factors with good retention ( $\geq 75 \%$ ). Statistical differences were assessed by Wald test $\mathrm{z}$ statistic. Factors in the adjusted model included: Sex, Race, Education, Transmission Route, Time-to-linkage, ART start date, Baseline CD4, Baseline log HIV-1 RNA, AIDS-defining Illness, Depression, Metabolic Disease, Hospitalizations, Year of linkage. All analyses were performed using R Statistical Software (R version 3.1.1).

\section{Results}

Between January 1, 2000 and June 30, 2011, 2,852 HIV-infected persons initiated care at the INI HIV/AIDS program, of which 54\% were $\geq 18$ years old, ART-naïve and had never participated in an HIV clinical trial. Of those participants, 151 were not linked to care, 107 died during the early care period and 39 became pregnant during the early care period. The resulting study population consisted of 1,251 HIV-infected persons, of which 1,049 were linked by laboratory results, 171 were linked by ART start date, and 31 were linked by both (Figure 1). 
Table 1 describes the study population overall and by retention group. The study population was $71 \%$ male, $48 \%$ non-white and had a median age of 35 years [interquartile range (IQR) $28,42]$. Approximately half of participants had $>8$ years of education, reported being heterosexual, and were linked to care $\mathfrak{3}$ months of their diagnosis. The majority initiated ART during early care (70\%). The median baseline CD4 was 330 cells $/ \mathrm{mm}^{3}$ (IQR 133, 522) and the median baseline log HIV-1 RNA was 4.65 (IQR 3.99, 5.21). Before the end of the early care period, more HIV-infected persons were diagnosed with a metabolic disease (49\%) than an AIDS-defining illness (41\%) or depression (15\%). Eighty percent $(\mathrm{N}=1,001)$ of the study population met criteria for good retention. Compared to the those with poor retention in early care, a larger proportion of participants achieving good retention were linked to care $\mathfrak{3}$ months after HIV diagnosis ( 51 vs. $43 \%, \mathrm{p}=0.02$ ), diagnosed with depression $(16$ vs. $12 \%, p=0.10)$, diagnosed with a metabolic disease $(51$ vs. $41 \%, p=$ 0.005 ) and had a baseline CD4 350 cells $/ \mathrm{mm}^{3}$ (52 vs. $42 \%, \mathrm{p}=0.04$ ) (Table 2).

Figure 2 illustrates the prevalence of good and poor retention in early HIV care over the study period. The proportion of newly linked individuals with good retention in care increased from $61 \%$ to $77 \%$ in 2000 and 2011, respectively. Table 2 shows the unadjusted and adjusted models for the association of socio-demographic and clinical factors with good retention. As chronological year of linkage increased so did the odds of good retention in early care [adjusted odds ratio $(\mathrm{AOR})=1.12 ; 95 \%$ confidence interval $(95 \% \mathrm{CI}) 1.07-1.18$ ] Compared to individuals $<30$ years of age, older individuals were more likely to have good retention $(30-40$ years $\mathrm{AOR}=1.63,95 \% \mathrm{CI} 1.16-2.32 ; 40-50$ years $\mathrm{AOR}=2.85,95 \% \mathrm{CI}$ $1.83-4.52 ;>50$ years $\mathrm{AOR}=2.37,95 \%$ CI $1.29-4.56$ ). Individuals who had $>8$ years of education ( $\mathrm{AOR}=1.97 ; 95 \% \mathrm{CI} 1.43-2.75)$ and initiated ART during the early care period were also more likely to have good retention ( $\_3$ months post-linkage AOR $=3.24,95 \% \mathrm{CI}$ $1.89-5.58 ; 3-24$ months post-linkage AOR $=1.59,95 \%$ CI 1.03-2.50). However, individuals with unknown HIV transmission route $(\mathrm{AOR}=0.22$ [0.10-0.48]) and unknown baseline CD4 (AOR=0.30; $95 \%$ CI 0.15-0.63) were less likely to achieve good retention. Metabolic disease, time-to-linkage and baseline CD4 350 cells $/ \mathrm{mm}^{3}$ were only associated with good retention in the unadjusted model. Hospitalization during early care was not associated with good retention.

\section{Discussion}

The present study addressed retention in early HIV care among HIV-infected persons from Rio de Janeiro, Brazil. Overall, we found the proportion of HIV-infected persons achieving good retention to be comparable to estimates from high-income settings. Although we identified individual- and clinic-level factors associated with good retention it is possible that system-level factors may have contributed to our finding of improved retention over time. Early ART initiation had the strongest association with good retention, further highlighting its importance as a foundation of HIV care. Importantly, socio-demographic factors associated with good retention suggest that there may be social and behavioral determinants of health influencing retention in early HIV care in this urban Brazilian population. 
It is encouraging that $80 \%$ of HIV-infected persons linked to care at INI from 2000 to 2011 achieved good retention. This estimate surpassed those from clinic-based and populationbased studies in the United States using comparable retention measures in which $68-72 \%$ of HIV-infected persons were retained in at least 3 out of 4 six-month intervals during the first two years in care $(8,10)$. Overall retention in early care improved over time; however, there seems to be two distinct periods from 2000-2002 and from 2003-2011 when the proportion of participants achieving good retention jumped from $54-61 \%$ to $77-89 \%$, respectively (Figure 2). It is possible that improved local infrastructure may have contributed to our findings. During the study period, INI hired 2 nurses dedicated to the HIV/AIDS clinical cohort, and CD4 and HIV RNA-1 testing availability increased as the cost of testing decreased and the capacity to conduct these tests increased. These local improvements likely increased laboratory monitoring and may have contributed to our observed increase in good retention over time. Additionally, country-wide outpatient service assessments from 2001 and 2007 found that the proportion of sites with adequate CD4 and HIV-1 RNA monitoring increased by $31 \%$ and $90 \%$ (27), respectively, indicating that CD4 and HIV RNA-1 testing became increasingly available over the study period. Our findings of high retention in early HIV care and its improvement over time are reassuring. Future studies are needed to understand the elements of healthcare infrastructure that may be impacting retention.

Initiating ART $s$ months post-linkage increased the odds of good retention more than threefold. HIV-infected persons who are on ART are likely more driven to engage in HIV care in order to evaluate viro-immunologic response. Although increased laboratory monitoring following ART initiation may explain improved retention, this effect would not be expected to last throughout the early care period. Importantly, Brazilian guidelines between 2000 and 2011 recommended ART initiation for those with a CD4 $\leq 350$ cells $/ \mathrm{mm}^{3}$ or for symptomatic HIV-infected persons (28). Encouragingly, later ART initiation was also associated with good retention indicating that participants who were ineligible for early ART initiation were likely returning during early care to evaluate eligibility. These findings reinforce the importance of early ART initiation, which has already been shown to prevent HIV transmission and improve HIV-related health outcomes (29-31). Notably, our findings suggest that retention in early HIV care should continue to improve as Brazil expands universal access to all HIV-infected persons regardless of CD4 (32).

We also identified socio-demographic factors associated with retention in early HIV care. First, having $\geq 8$ years of education doubled the odds of having good retention. Education has increasing relevance to the AIDS epidemic in Brazil as there is a growing proportion of HIV-infected persons with lower education level $(33,34)$. In Brazil, behavioral and social factors associated with lower education level include lower socio-economic status (35), poorer health literacy (36), less healthcare utilization (35), alcohol dependence (37) and STD risk behaviors $(38,39)$. Lower education level has also been associated with poor HIV-related outcomes, such as virologic failure and poor ART adherence (40-42). Thus, in Brazil, education is an indicator of social and behavioral determinants of health, which likely contribute to disparities in HIV related outcomes and retention in early care. Furthermore, participants with lower education level may also be more likely to have unmet support service needs, such as housing and employment assistance, which have been shown to be substantial barriers to retention in HIV care $(43,44)$. Clinic-based ancillary services 
addressing unmet needs have been shown to improve retention in HIV care (45-47). Our findings suggest that addressing the needs of HIV-infected persons with lower education level will likely play an important role in controlling the AIDS epidemic in Brazil.

Another factor significantly associated with good retention was age. Consistent with retention studies in high-income settings (8-10), older individuals were more likely to achieve good retention in early care. Young adults are more likely to have poor adherence to ART $(40,42,48)$ and suffer poor HIV-related outcomes, such as virologic failure and virologic rebound (49). However, compared to older age groups, young adults are more likely to experience viral suppression associated with improved retention in HIV care (7). Thus, retention in early HIV care may be particularly important for younger age groups. HIV-related stigma has been found to play a role in poor ART adherence and nondisclosure of HIV status among young adults (50,51), and may also explain why younger HIV-infected persons experience poor retention in early care at INI. Case management, peer-patient navigation systems and co-located services that recognize the unique needs of younger HIVinfected persons are promising models to address age-specific barriers to retention in early care (52-54).

Lastly, we found unknown baseline CD4 and unknown transmission route to be associated with reduced odds of achieving good retention. Further analysis showed that participants with unknown baseline CD4 were linked to care earlier during the study period, which supports the hypothesis that improved local infrastructure may have contributed to improved retention over time (data not shown). In regards to transmission route, participants with unknown transmission route consisted solely of men. We suspect that unknown transmission route might have resulted from non-disclosure. Both unknown baseline CD4 and unknown transmission route have been previously associated with poor retention $(17,55)$. Given the low number of participants in these groups, however, we cannot confidently draw inferences about these associations.

This study has a number of limitations. First, the inexistence of a longitudinal database of clinic visits forced us to use CD4 and HIV RNA-1 testing results as surrogate for clinic visits. Though this approach has been used in other studies $(10,16,24)$, it is possible that, in the present study, retention was underestimated in periods when testing was less available for structural reasons, as cited above. Thus, it is particularly reassuring that despite these limitations, our estimates of retention in care were as high as those found in high-income settings. Other limitations include the cross-sectional nature of the study precluding inferences about causality, and the fact that this was a clinic-based study so that findings may not be generalizable to other populations. Furthermore, socio-demographic data recorded at the first clinic visit may have been influenced by HIV care providers entering information into the medical chart. Lastly, we were not able to take into account substance abuse and transgender identity, which have both been shown to influence retention in HIV care $(8,9,56)$. Future studies are necessary to investigate how these factors are associated with retention in early HIV care. 


\section{Conclusions}

In summary, retention in early HIV care was high and improved over time in this urban Brazilian cohort. Interventions aimed at improving retention in early HIV care should prioritize less-educated and younger HIV-infected persons. This study demonstrated the feasibility of using laboratory results to longitudinally monitor retention in early HIV care in Brazil at the clinic-level. Applying similar approaches at regional or national levels may further inform structural and programmatic efforts aimed at optimizing HIV care in developing country settings.

\section{Acknowledgments}

We would like to thank all the participants enrolled in the INI HIV/AIDS program, as well as the hard working and dedicated staff at INI. We would also like to thank Eddy Segura for his assistance in translating our abstract into Spanish. Support for DS provided by the NIH R25 MH087222 (South American Program in HIV Prevention Research), the Infectious Disease Society of America and the American Society of Tropical Medicine and Hygiene. Support for JEL provided by the NIH K23 AI110532. PL and BG acknowledge funding from the National Council of Technological and Scientific Development $(\mathrm{CNPq})$ and the Research Funding Agency of the State of Rio de Janeiro (FAPERJ)

\section{References}

1. Giordano TP, Gifford AL, White AC, et al. Retention in care: a challenge to survival with HIV infection. Clin Infect Dis. Jun 1; 2007 44(11):1493-1499. [PubMed: 17479948]

2. Geng EH, Nash D, Kambugu A, et al. Retention in care among HIV-infected patients in resourcelimited settings: emerging insights and new directions. Curr HIV/AIDS Rep. Nov; 2010 7(4):234244. [PubMed: 20820972]

3. Mugavero MJ, Norton WE, Saag MS. Health care system and policy factors influencing engagement in HIV medical care: piecing together the fragments of a fractured health care delivery system. Clin Infect Dis. Jan 15; 2011 52( Suppl 2):S238-246. [PubMed: 21342913]

4. Metsch LR, Pereyra M, Messinger S, et al. HIV transmission risk behaviors among HIV-infected persons who are successfully linked to care. Clin Infect Dis. Aug 15; 2008 47(4):577-584. [PubMed: 18624629]

5. Crawford TN, Sanderson WT, Breheny P, Fleming ST, Thornton A. Impact of non-HIV related comorbidities on retention in HIV medical care: does retention improve over time? AIDS Behav. Mar; 2014 18(3):617-624. [PubMed: 23695522]

6. Mugavero MJ, Amico KR, Westfall AO, et al. Early retention in HIV care and viral load suppression: implications for a test and treat approach to HIV prevention. J Acquir Immune Defic Syndr. Jan 1; 2012 59(1):86-93. [PubMed: 21937921]

7. Yehia BR, Rebeiro P, Althoff KN, et al. The Impact of Age on Retention in Care and Viral Suppression. J Acquir Immune Defic Syndr. Dec 31.2014

8. Ulett KB, Willig JH, Lin HY, et al. The therapeutic implications of timely linkage and early retention in HIV care. AIDS Patient Care STDS. Jan; 2009 23(1):41-49. [PubMed: 19055408]

9. Giordano TP, Hartman C, Gifford AL, Backus LI, Morgan RO. Predictors of retention in HIV care among a national cohort of US veterans. HIV Clin Trials. Sep-Oct;2009 10(5):299-305. [PubMed: 19906622]

10. Tripathi A, Youmans E, Gibson JJ, Duffus WA. The impact of retention in early HIV medical care on viro-immunological parameters and survival: a statewide study. AIDS Res Hum Retroviruses. Jul; 2011 27(7):751-758. [PubMed: 21142607]

11. Boletim Epidemiológico-AIDS e DST. Secretariat of Health Surveillance Brazilian Ministry of Health Department of STD AIDS and Viral Hepatitis; 2014.

12. CDC. Vital Signs: HIV Diagnosis, Care, and Treatment Among Persons Living with HIV - United States, 2011. MMWR. 2014; 63:1113-1117. [PubMed: 25426654] 
13. Rosen S, Fox M. Retention in HIV Care between Testing and Treatment in Sub-Saharan Africa: A Systematic Review. PLoS Med. 2011; 8(7):e1001056. [PubMed: 21811403]

14. Mugavero MJ, Davila JA, Nevin CR, Giordano TP. From access to engagement: measuring retention in outpatient HIV clinical care. AIDS Patient Care STDS. Oct; 2010 24(10):607-613. [PubMed: 20858055]

15. Mugavero MJ, Westfall AO, Zinski A, et al. Measuring retention in HIV care: the elusive gold standard. J Acquir Immune Defic Syndr. Dec 15; 2012 61(5):574-580. [PubMed: 23011397]

16. Crawford TN, Sanderson WT, Thornton A. A comparison study of methods for measuring retention in HIV medical care. AIDS Behav. Nov; 2013 17(9):3145-3151. [PubMed: 23868692]

17. Yehia BR, Fleishman JA, Metlay JP, et al. Comparing different measures of retention in outpatient HIV care. AIDS. Jun 1; 2012 26(9):1131-1139. [PubMed: 22382143]

18. Rosen S, Fox MP, Gill CJ. Patient retention in antiretroviral therapy programs in sub-Saharan Africa: a systematic review. PLoS Med. Oct 16.2007 4(10):e298. [PubMed: 17941716]

19. Boletim Epidemiologico-AIDS e DST. Secretariat of Health Surveillance Brazilian Ministry of Health Department of STD AIDS and Viral Hepatitis; 2013.

20. Grinsztejn B, Veloso VG, Friedman RK, et al. Early mortality and cause of deaths in patients using HAART in Brazil and the United States. AIDS. Oct 23; 2009 23(16):2107-2114. [PubMed: 19770698]

21. Moreira RI, Luz PM, Struchiner CJ, et al. Immune status at presentation for HIV clinical care in Rio de Janeiro and Baltimore. J Acquir Immune Defic Syndr. Aug; 2011 57( Suppl 3):S171-178. [PubMed: 21857314]

22. Grinsztejn B, Veloso VG, Pilotto JH, Campos DP, Keruly JC, Moore RD. Comparison of clinical response to initial highly active antiretroviral therapy in the patients in clinical care in the United States and Brazil. J Acquir Immune Defic Syndr. Aug 15; 2007 45(5):515-520. [PubMed: 17558332]

23. Protocolo clínico e diretrizes terapêuticas para manejo da infecção pelo HIV em adultos. Brazilian Ministry of Health Department of STD, AIDS and Viral Hepatitis; 2013.

24. Cohen SM, Hu X, Sweeney P, Johnson AS, Hall HI. HIV viral suppression among persons with varying levels of engagement in HIV medical care, 19 US jurisdictions. J Acquir Immune Defic Syndr. Dec 15; 2014 67(5):519-527. [PubMed: 25230292]

25. Reveles KR, Juday TR, Labreche MJ, et al. Comparative value of four measures of retention in expert care in predicting clinical outcomes and health care utilization in HIV patients. PLoS One. 2015; 10(3):e0120953. [PubMed: 25794182]

26. MMWR Recomm Rep. Vol. 41. Centers for Disease Control and Prevention; 1993. Revised Classification Systems for HIV Infection and Expanded Surveillance Case Definition for AIDS Among Adolescents and Adults.

27. Nemes MI, Alencar TM, Basso CR, et al. Assessment of outpatient services for AIDS patients, Brazil: comparative study 2001/2007. Rev Saude Publica. Feb; 2013 47(1):137-146. discussion 146. [PubMed: 23703140]

28. Recomendações para terapia anti-retroviral em adultos infectados pelo HIV. Brazilian Ministry of Health Deptartment, National AIDS and STDs Program; 2008.

29. Grinsztejn B, Hosseinipour MC, Ribaudo HJ, et al. Effects of early versus delayed initiation of antiretroviral treatment on clinical outcomes of HIV-1 infection: results from the phase 3 HPTN 052 randomised controlled trial. Lancet Infect Dis. Apr; 2014 14(4):281-290. [PubMed: 24602844]

30. Group ISS. Initiation of Antiretroviral Therapy in Early Asymptomatic HIV Infection. N Engl J Med. Aug 27; 2015 373(9):795-807. [PubMed: 26192873]

31. Cohen MS, Chen YQ, McCauley M, et al. Prevention of HIV-1 infection with early antiretroviral therapy. N Engl J Med. Aug 11; 2011 365(6):493-505. [PubMed: 21767103]

32. UNAIDS Global AIDS Response Progress Reporting. Brazil: Secretariat of Health Surveillance Brazilian Ministry of Health Deptartment of STD AIDS and Viral Hepatitis; 2014.

33. Brito AM, Castilho EA, Szwarcwald CL. Regional patterns of the temporal evolution of the AIDS epidemic in Brazil following the introduction of antiretroviral therapy. Braz J Infect Dis. Feb; 2005 9(1):9-19. [PubMed: 15947842] 
34. Berkman A, Garcia J, Munoz-Laboy M, Paiva V, Parker R. A critical analysis of the Brazilian response to HIV/AIDS: lessons learned for controlling and mitigating the epidemic in developing countries. Am J Public Health. Jul; 2005 95(7):1162-1172. [PubMed: 15933232]

35. Szwarcwald CL, Souza-Junior PR, Damacena GN. Socioeconomic inequalities in the use of outpatient services in Brazil according to health care need: evidence from the World Health Survey. BMC Health Serv Res. 2010; 10:217. [PubMed: 20653970]

36. Carthery-Goulart MT, Anghinah R, Areza-Fegyveres R, et al. Performance of a Brazilian population on the test of functional health literacy in adults. Rev Saude Publica. Aug; 2009 43(4): 631-638. [PubMed: 19488667]

37. Silveira CM, Viana MC, Siu ER, de Andrade AG, Anthony JC, Andrade LH. Sociodemographic correlates of transitions from alcohol use to disorders and remission in the Sao Paulo megacity mental health survey, Brazil. Alcohol and Alcoholism. May-Jun;2011 46(3):324-332. [PubMed: 21414952]

38. Silveira MF, Beria JU, Horta BL, Tomasi E, Victora CG. Factors associated with risk behaviors for sexually transmitted disease/AIDS among urban Brazilian women: a population-based study. Sex Transm Dis. Sep; 2002 29(9):536-541. [PubMed: 12218846]

39. de Souza CT, Diaz T, Sutmoller F, Bastos FI. The association of socioeconomic status and use of crack/cocaine with unprotected anal sex in a cohort of men who have sex with men in Rio de Janeiro, Brazil. J Acquir Immune Defic Syndr. Jan 1; 2002 29(1):95-100. [PubMed: 11782596]

40. Cardoso SW, Luz PM, Velasque L, et al. Effectiveness of first-line antiretroviral therapy in the IPEC cohort, Rio de Janeiro, Brazil. AIDS Res Ther. 2014; 11:29. [PubMed: 25206924]

41. Nemes MI, Carvalho HB, Souza MF. Antiretroviral therapy adherence in Brazil. AIDS. Jun; 2004 18( Suppl 3):S15-20. [PubMed: 15322479]

42. Cardoso SW, Luz PM, Velasque L, et al. Outcomes of second-line combination antiretroviral therapy for HIV-infected patients: a cohort study from Rio de Janeiro, Brazil. BMC Infect Dis. 2014; 14:699. [PubMed: 25523385]

43. Tobias CR, Cunningham W, Cabral HD, et al. Living with HIV but without medical care: barriers to engagement. AIDS Patient Care STDS. Jun; 2007 21(6):426-434. [PubMed: 17594252]

44. Gardner LI, Giordano TP, Marks G, et al. Enhanced personal contact with HIV patients improves retention in primary care: a randomized trial in 6 US HIV clinics. Clin Infect Dis. Sep 1; 2014 59(5):725-734. [PubMed: 24837481]

45. Ashman JJ, Conviser R, Pounds MB. Associations between HIV-positive individuals' receipt of ancillary services and medical care receipt and retention. AIDS Care. Aug; 2002 14( Suppl 1):S109-118. [PubMed: 12204145]

46. Lo W, MacGovern T, Bradford J. Association of ancillary services with primary care utilization and retention for patients with HIV/AIDS. AIDS Care. Aug; 2002 14( Suppl 1):S45-57. [PubMed: 12204141]

47. Messeri PA, Abramson DM, Aidala AA, Lee F, Lee G. The impact of ancillary HIV services on engagement in medical care in New York City. AIDS Care. Aug; 2002 14( Suppl 1):S15-29. [PubMed: 12204139]

48. Barclay TR, Hinkin CH, Castellon SA, et al. Age-associated predictors of medication adherence in HIV-positive adults: health beliefs, self-efficacy, and neurocognitive status. Health Psychol. Jan; 2007 26(1):40-49. [PubMed: 17209696]

49. Ryscavage P, Anderson EJ, Sutton SH, Reddy S, Taiwo B. Clinical outcomes of adolescents and young adults in adult HIV care. J Acquir Immune Defic Syndr. Oct 1; 2011 58(2):193-197. [PubMed: 21826014]

50. Rao D, Kekwaletswe TC, Hosek S, Martinez J, Rodriguez F. Stigma and social barriers to medication adherence with urban youth living with HIV. AIDS Care. Jan; 2007 19(1):28-33. [PubMed: 17129855]

51. Dowshen N, Binns HJ, Garofalo R. Experiences of HIV-related stigma among young men who have sex with men. AIDS Patient Care STDS. May; 2009 23(5):371-376. [PubMed: 19320600]

52. Naar-King S, Green M, Wright K, Outlaw A, Wang B, Liu H. Ancillary services and retention of youth in HIV care. AIDS Care. Feb; 2007 19(2):248-251. [PubMed: 17364406] 
53. Wohl AR, Garland WH, Wu J, et al. A youth-focused case management intervention to engage and retain young gay men of color in HIV care. AIDS Care. Aug; 2011 23(8):988-997. [PubMed: 21390879]

54. Davila JA, Miertschin N, Sansgiry S, Schwarzwald H, Henley C, Giordano TP. Centralization of HIV services in HIV-positive African-American and Hispanic youth improves retention in care. AIDS Care. 2013; 25(2):202-206. [PubMed: 22708510]

55. Olatosi BA, Probst JC, Stoskopf CH, Martin AB, Duffus WA. Patterns of engagement in care by HIV-infected adults: South Carolina, 2004-2006. AIDS. Mar 27; 2009 23(6):725-730. [PubMed: 19197194]

56. Sevelius JM, Patouhas E, Keatley JG, Johnson MO. Barriers and facilitators to engagement and retention in care among transgender women living with human immunodeficiency virus. Ann Behav Med. Feb; 2014 47(1):5-16. [PubMed: 24317955] 


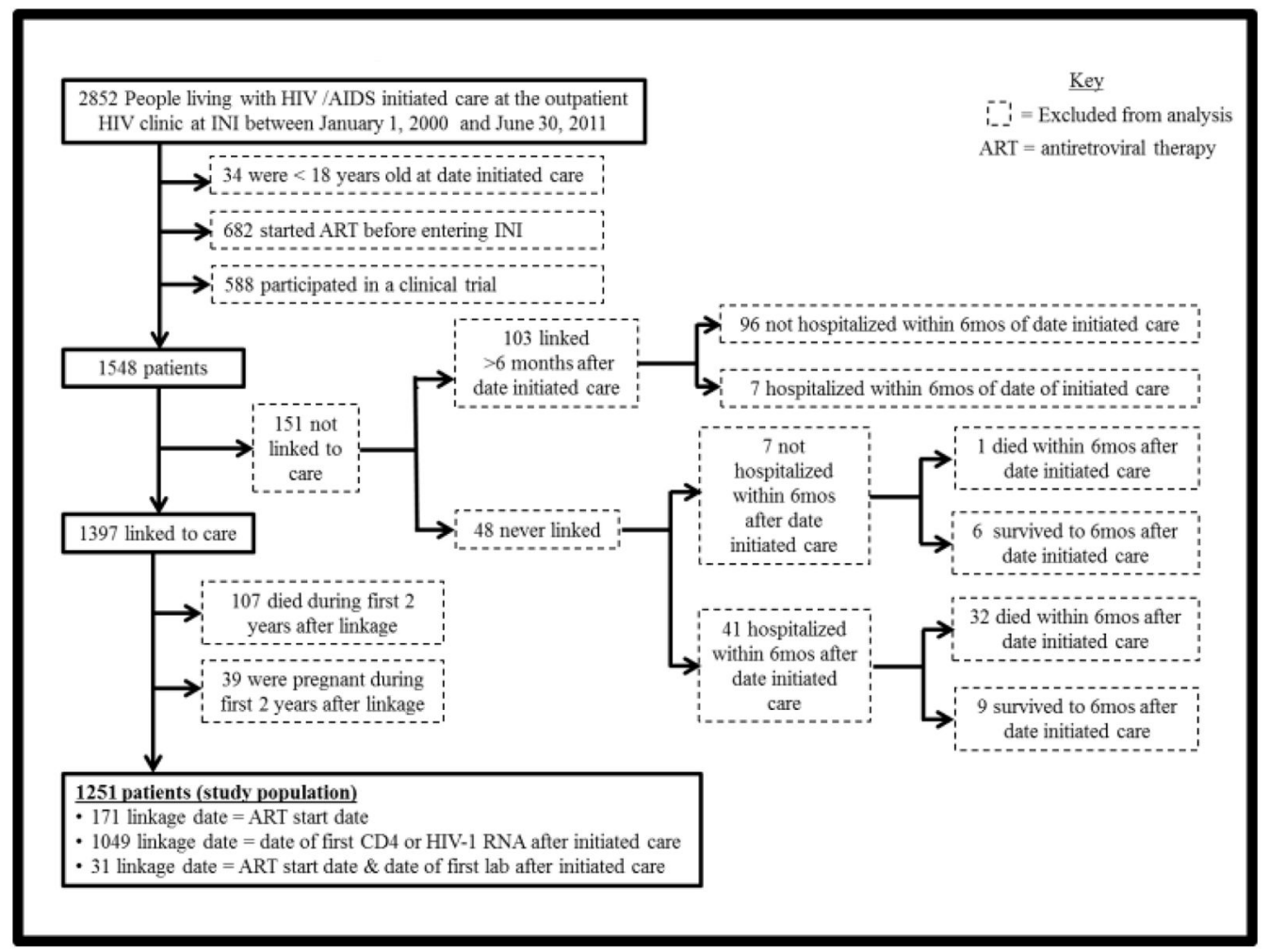

Figure 1.

Flowchart of inclusion and exclusion criteria 


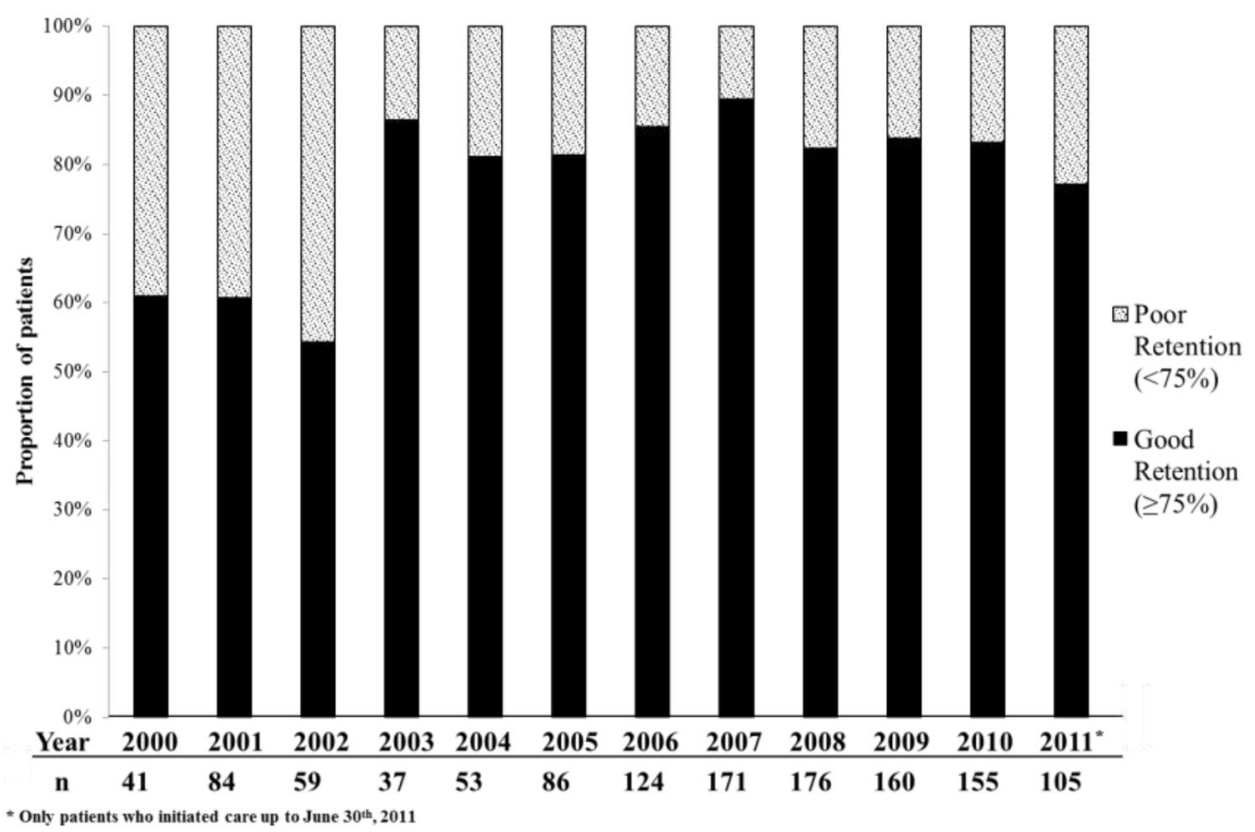

Figure 2.

Retention in early care among participants linked to care at the HIV outpatient clinic at INI, 2000-2011 


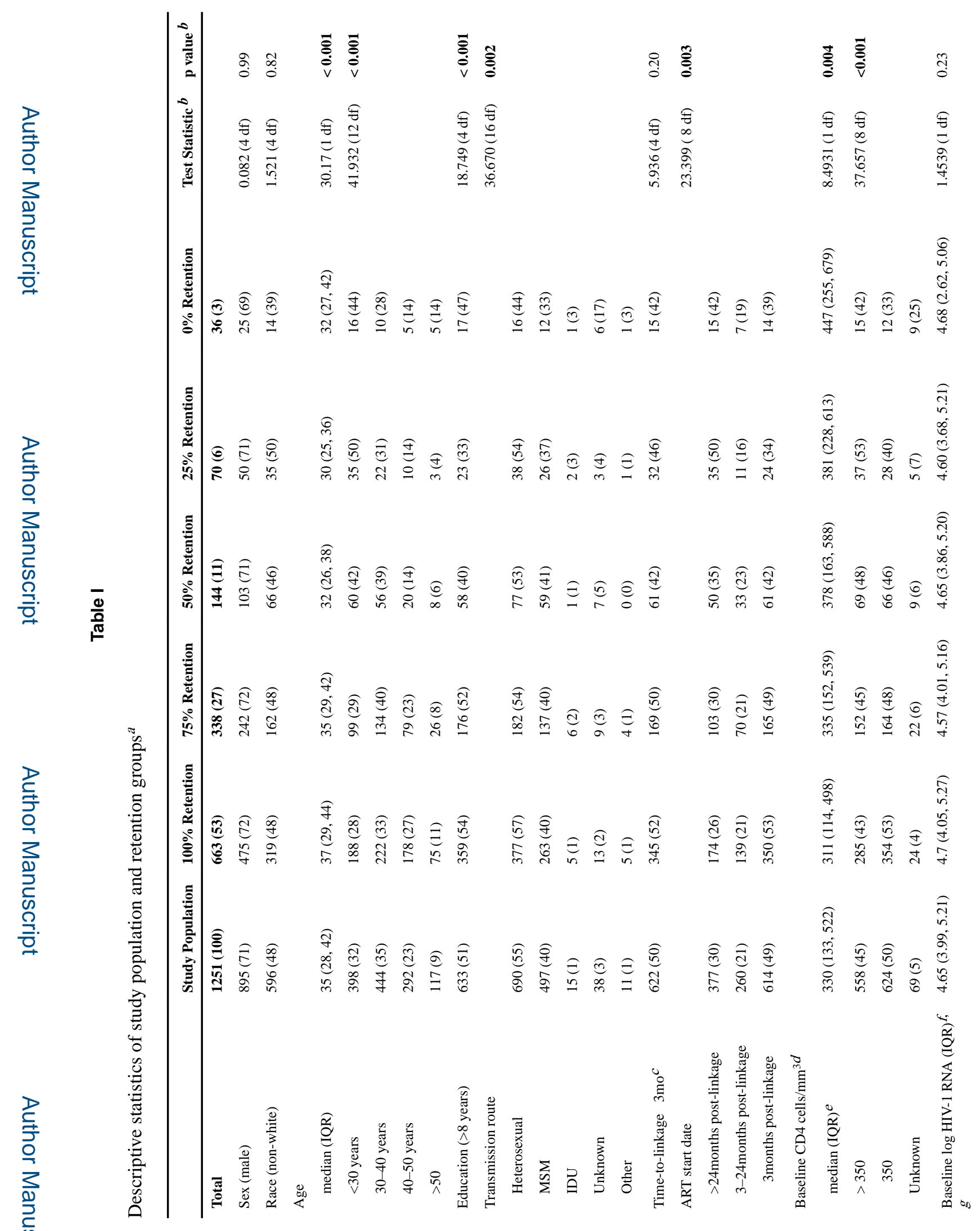


Silva et al.

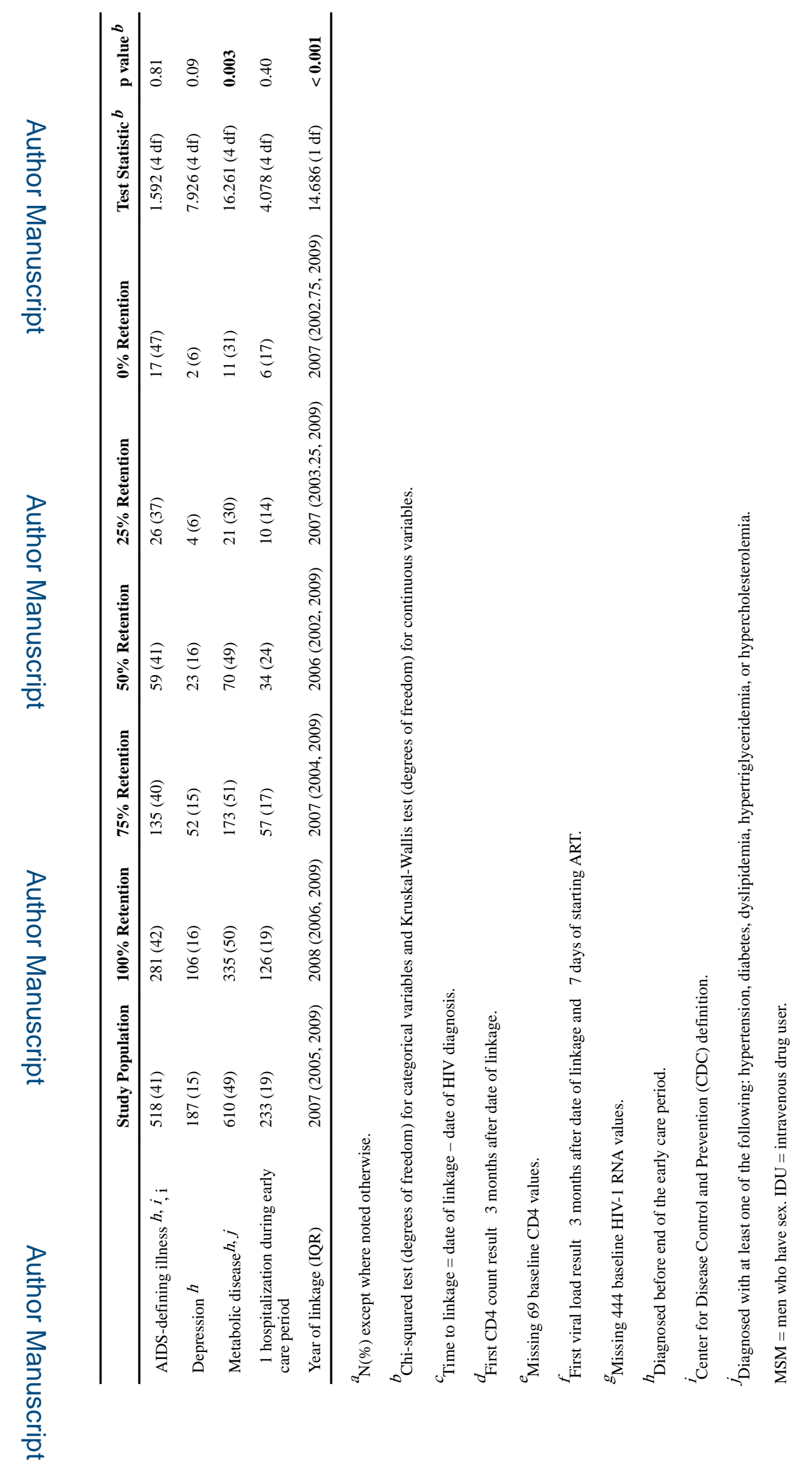

AIDS Behav. Author manuscript; available in PMC 2017 May 01. 


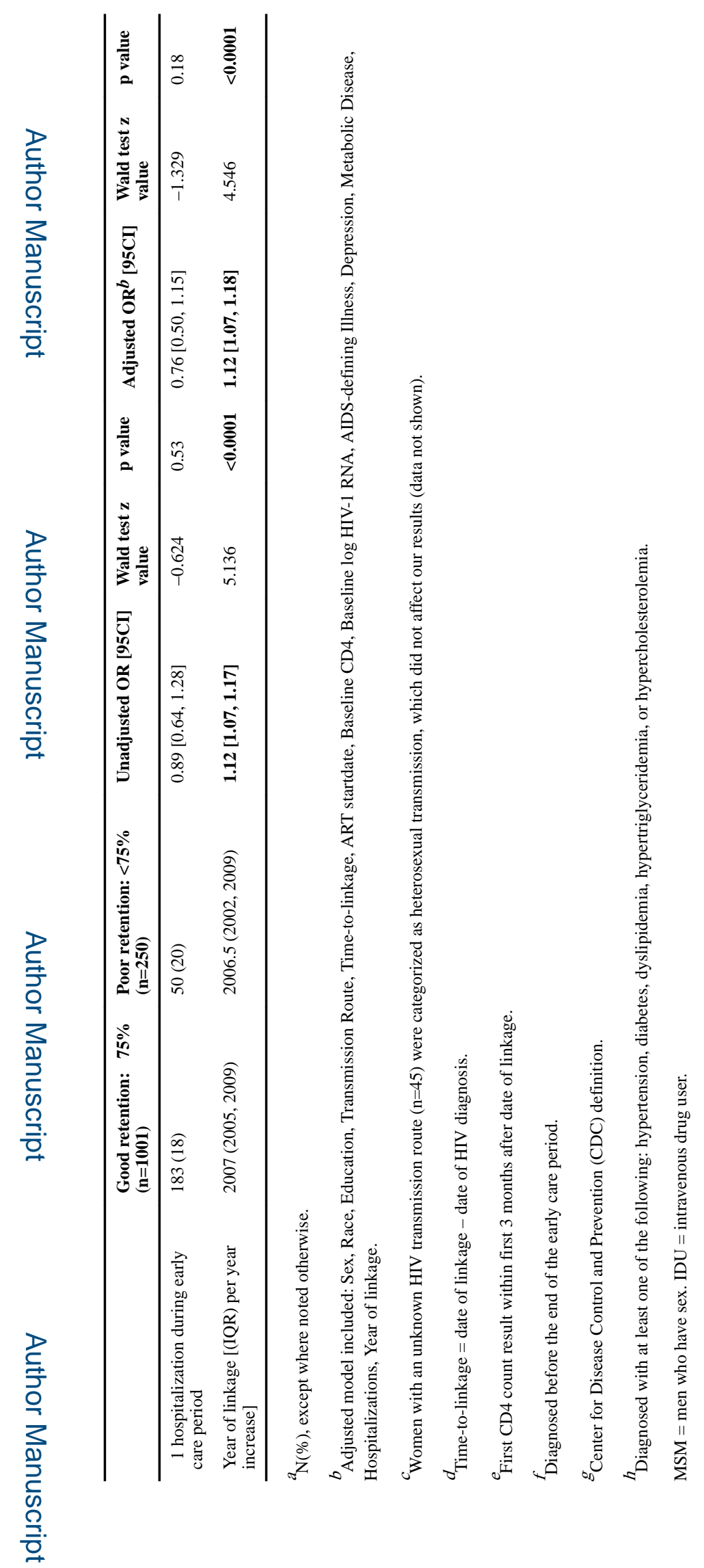

AIDS Behav. Author manuscript; available in PMC 2017 May 01. 